\title{
The orphan receptor ALK7 and the Activin receptor ALK4 mediate signaling by Nodal proteins during vertebrate development
}

\author{
Eva Reissmann, ${ }^{1,2}$ Henrik Jörnvall, ${ }^{1,4}$ Andries Blokzijl, ${ }^{1,4}$ Olov Andersson, ${ }^{1}$ Chenbei Chang, ${ }^{2}$ \\ Gabriella Minchiotti, ${ }^{3}$ M. Graziella Persico, ${ }^{3}$ Carlos F. Ibáñez, ${ }^{1,5}$ and Ali H. Brivanlou ${ }^{2}$ \\ ${ }^{1}$ Division of Molecular Neurobiology, Department of Neuroscience, Karolinska Institute, S-17177 Stockholm, Sweden; \\ ${ }^{2}$ Laboratory of Molecular Vertebrate Embryology, The Rockefeller University, New York, New York 10021-6399, USA; \\ ${ }^{3}$ International Institute of Genetics and Biophysics, CNR, 80125 Naples, Italy
}

\begin{abstract}
Nodal proteins have crucial roles in mesendoderm formation and left-right patterning during vertebrate development. The molecular mechanisms of signal transduction by Nodal and related ligands, however, are not fully understood. In this paper, we present biochemical and functional evidence that the orphan type I serine/threonine kinase receptor ALK7 acts as a receptor for mouse Nodal and Xenopus Nodal-related 1 (Xnr1). Receptor reconstitution experiments indicate that ALK7 collaborates with ActRIIB to confer responsiveness to Xnr1 and Nodal. Both receptors can independently bind Xnr1. In addition, Cripto, an extracellular protein genetically implicated in Nodal signaling, can independently interact with both Xnr1 and ALK7, and its expression greatly enhances the ability of ALK7 and ActRIIB to respond to Nodal ligands. The Activin receptor ALK4 is also able to mediate Nodal signaling but only in the presence of Cripto, with which it can also interact directly. A constitutively activated form of ALK7 mimics the mesendoderm-inducing activity of Xnr1 in Xenopus embryos, whereas a dominant-negative ALK7 specifically blocks the activities of Nodal and Xnr1 but has little effect on other related ligands. In contrast, a dominant-negative ALK4 blocks all mesoderm-inducing ligands tested, including Nodal, Xnr1, Xnr2, Xnr4, and Activin. In agreement with a role in Nodal signaling, ALK7 mRNA is localized to the ectodermal and organizer regions of Xenopus gastrula embryos and is expressed during early stages of mouse embryonic development. Therefore, our results indicate that both ALK4 and ALK7 can mediate signal transduction by Nodal proteins, although ALK7 appears to be a receptor more specifically dedicated to Nodal signaling.
\end{abstract}

[Key Words: Mesendoderm; TGF- $\beta$; ActRIIB; Xnr1; Oep; Cripto]

Received February 27, 2001; revised version accepted June 6, 2001.

One of the earliest induction events in the vertebrate embryo involves the formation of the mesodermal and endodermal germ layers (Kimelman and Griffin 2000). Members of the TGF- $\beta$ superfamily, in particular Activin, Nodal and Nodal-related ligands, play important roles in mesendoderm determination (for review, see Harland and Gerhart 1997). Activin was the first factor to be postulated as a mesendoderm-inducing agent, because of its ability to activate different types of mesodermal tissues in a concentration dependent manner (Gurdon et al. 1994, 1995). A role for endogenous Activin during early mesendoderm induction, however, has remained controversial (Schulte-Merker et al. 1994; Mat-

\footnotetext{
${ }^{4}$ These authors contributed equally to this work.

${ }^{5}$ Corresponding author.

E-MAIL carlos.ibanez@neuro.ki.se; FAX 46-8-339548.

Article and publication are at http://www.genesdev.org/cgi/doi/10.1101/ $\operatorname{gad} .201801$.
}

zuk et al. 1995a; Dyson and Gurdon 1997). On the other hand, genetic experiments in mouse and zebrafish have suggested that Nodal and its related factors are required for mesendoderm formation (Zhou et al. 1993; Conlon et al. 1994; Erter et al. 1998; Feldman et al. 1998; Rebagliati et al. 1998a,b; Sampath et al. 1998). Mice lacking Nodal, the only family member identified in mammals, die shortly after gastrulation without any visible sign of node formation (Zhou et al. 1993; Conlon et al. 1994). In the zebrafish, mutation of the squint and cyclops genes, encoding two Nodal-related proteins, results in axial malformations and head defects, including a fused midline and cyclopia (Hatta et al. 1991; Heisenberg and Nuesslein-Volhard 1997; Erter et al. 1998; Feldman et al. 1998; Rebagliati et al. 1998a,b; Sampath et al. 1998). In amphibians, overexpression of mouse Nodal and the Xenopus Nodal-related factors 1, 2, and 4 (Xnr1, 2, 4) in ectodermal explants induces mesendodermal tissue, whereas overexpression in ventral regions mimics the organizer activity by inducing a secondary axis that con- 
tains dorsal mesodermal tissue such as muscle and notochord (Jones et al. 1995; Joseph and Melton 1997). On the other hand, inhibition of Nodal signaling blocks mesoderm induction in Xenopus embryos (Piccolo et al. 1999; Agius et al. 2000) and prevents endoderm formation in the vegetal region (Osada and Wright 1999).

Analysis of the zebrafish mutant one-eyed pinhead $(o e p)$ revealed a very surprising phenotype, resembling in all aspects to the double mutant for squint and cyclops, suggesting a role for the product of the oep gene in Nodal signaling. In agreement with these results, mutation of the closely related mouse gene Cripto also abolishes mesendoderm formation (Ding et al. 1998). The product of the Cripto gene encode a glycosyl-phosphatydilinositol (GPI)-anchored protein containing an epidermal growth factor (EGF) repeat and a cysteine-rich region, the CFC domain (Minchiotti et al. 2000), suggesting that it could represent an extracellular co-factor for Nodal signaling. The precise molecular role of EGF-CFC proteins in Nodal signaling is, however, unknown.

Although genetic experiments have suggested that endogenous Activin is not required for mesendoderm formation, its ability to induce mesodermal markers on overexpression in the early embryo indicates that this protein may activate some component of the Nodal signaling pathway, including putative Nodal receptors. Similar to other members of the TGF- $\beta$ superfamily, Nodal-related proteins are believed to signal via a heteromeric receptor complex consisting of type I and type II serine/threonine kinase receptors (for review, see Massagué 1998). Although both type I and type II receptors cooperate to ligand binding, specificity is determined by the type I receptor. Loss-of-function and gain-of-function experiments have indicated a possible role for the Activin receptors ActRIIB and ALK4 in Nodal signaling. Mice lacking ActRIIB have defects in left-right axis formation, a characteristic Nodal activity, and the double knockout of ActRIIA and ActRIIB shows several of the typical Nodal loss-of-function deficits (Oh and Li 1997; Song et al. 1999). Gain-of-function experiments with constitutively activated forms of type I receptors have demonstrated the ability of many members of this receptor family to induce mesendoderm (Mahony and Gurdon 1995; Chang et al. 1997; Mahony et al. 1998; Ramsdell and Yost 1999; Shi et al. 2000). So far only ALK4 has been shown to induce formation of a secondary axis in whole embryos (Armes and Smith 1997), however. Moreover, the phenotype of a null mutation in the mouse ALK4 gene resembles that of the Nodal knockout (Gu et al. 1998), providing genetic evidence in support of a role for ALK4 in signaling by Nodal proteins. It is still unknown, however, whether ActRIIB and ALK4 are in fact able to bind Nodal proteins or to reconstitute Nodal signaling in unresponsive cells.

The orphan type I receptor ALK7 is predominantly expressed in distinct subpopulations of cells in the vertebrate central nervous system during postnatal development (Rydén et al. 1996; Tsuchida et al. 1996). ALK7 is similar in its serine/threonine kinase domain to ALK4 and ALK5, but very divergent in its extracellular domain from all ALKs (Rydén et al. 1996), suggesting similar signaling properties to TGF- $\beta$ and Activin receptors but different ligand specificity. In agreement with this, ALK7 is unable to bind TGF- $\beta$, Activin, or BMP7, even in the presence of the corresponding type II receptors T $\beta$ RII, ActRIIA, and BMPRII, respectively (Rydén et al. 1996). ALK7 signaling, studied using a constitutively active mutant receptor, also resembles that of Activin and TGF- $\beta$ in that it activates Smad2 and Smad3, but not Smad1 (Watanabe et al. 1999; Jörnvall et al. 2001).

In this study, we have investigated a possible role of ALK7 during early vertebrate development using gain- and loss-of-function experiments in Xenopus embryos in direct comparison to ALK4. Prompted by the results of these studies, we went on to investigate the roles of ALK7 and ALK4 in signaling by Nodal and related proteins using binding and receptor reconstitution assays. Our results demonstrate that ALK7 is a receptor for Nodal, and provide evidence supporting a functional role for this receptor during vertebrate development.

\section{Results}

An ALK7 gain-of-function mutant induces mesoderm and endoderm formation

Mutation of Thr into Asp at position 194 in the intracellular juxtamembrane region of ALK7 results in its constitutive activation in the absence of ligand or type II receptors (Tsuchida et al. 1996; Jörnvall et al. 2001). RNA encoding constitutively active rat ALK7 (CAALK7) was microinjected into the animal pole of Xenopus embryos and ectodermal explants (animal caps) were isolated at blastula stages. Injection of CA-ALK7 induced elongation of ectodermal explants at gastrula stages, reflecting morphogenetic changes in response to ALK7 signaling (Fig. 1A). The elongation of animal caps is often associated with mesoderm induction. Analysis of explants for expression of cell type-specific markers by RTPCR (Fig. 1B) revealed a dose-dependent induction of mesodermal markers, including cardiac actin (muscle), collagen type II (notochord), HoxB9 (lateral plate mesoderm), and the endodermal marker Xlhbox8 (Mohun et al. 1986; Hemmati-Brivanlou et al. 1994; Lemaire et al. 1998). Expression of the pan-neural marker NCAM was also detected (Hemmati-Brivanlou and Melton 1994), probably attributable to secondary induction by axial mesoderm (Fig. 1B). In vivo, injection of RNA encoding CA-ALK7 into a ventral-vegetal cell of eight-cell stage embryos induced the formation of a partial secondary axis in $58 \%$ of injected embryos $(n=77)$ containing muscle and notochord expressing the injected gene (data not shown).

The induction of mesendodermal markers in animal caps by CA-ALK7 resembles effects obtained previously with activated ALK4 (Armes and Smith 1997; Chang et al. 1997), and mimics the activities of Activin and 
Reissmann et al.

Figure 1. Functional characterization of ALK7 by gain-of-function experiments in Xenopus laevis. (A) Morphology of animal caps expressing the constitutively active mutant form of rat ALK7 (CA-ALK7). Embryos were injected in the animal pole at the two-cell stage, animal cap explants were dissected at the blastula stage and allowed to develop until sibling control embryos reached tailbud stage 25. (B) Doseresponse induction of mesendodermal marker genes in animal caps injected with increasing concentrations of CA-ALK7. Embryos were injected at the two-cell stage, animal cap explants were dissected at the blastula stage, and harvested at stage 25. EF1 $\alpha$ is shown as loading control. (-RT) No reverse transcriptase; (E) total embryo; (un) uninjected control explants. Data are representative of four independent experiments. (C) CA-ALK7 and CAALK4 induce early mesendodermal marker genes in a dose-responsive manner. RT-PCR analyses took place at the gastrula stage. (D) CA-ALK7 and CAALK4 both elicit late mesodermal marker genes, but show differences in their ability to maintain expression of $X n r$ genes in ectodermal explants. RT-PCR analyses were performed at the tailbud stage (stage 20).
A

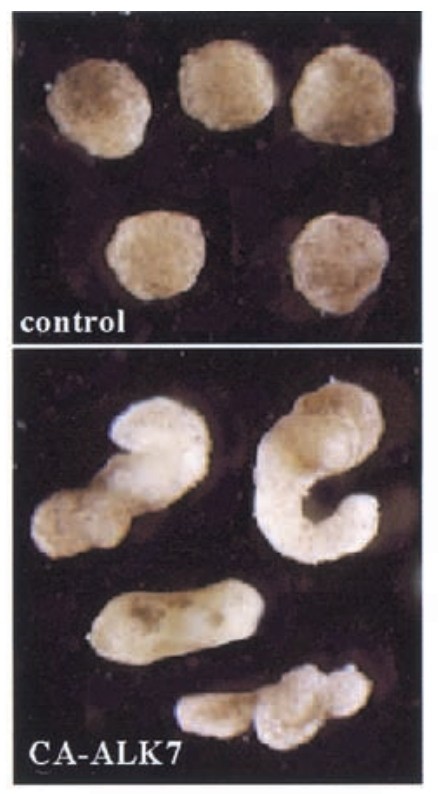

C
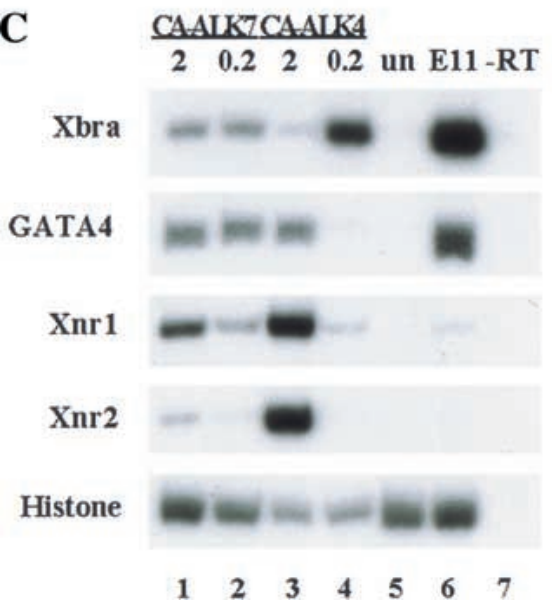

B
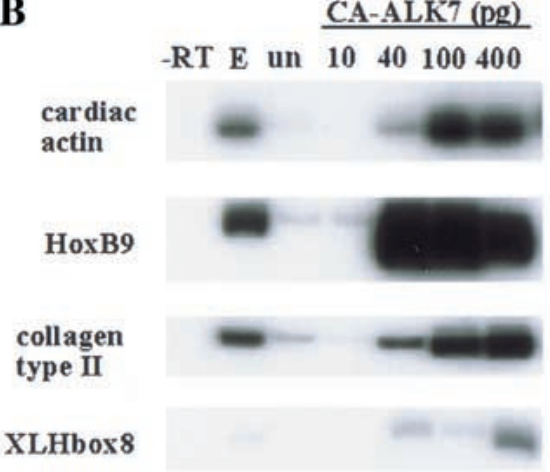

Ncam

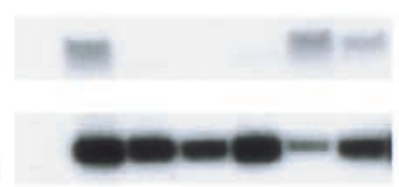

$\begin{array}{lllllll}1 & 2 & 3 & 4 & 5 & 6 & 7\end{array}$

D

CAALKZ CA.ALK4

$\begin{array}{lllll}2 & 0.2 & 2 & 0.2 & \text { un E20-RT }\end{array}$

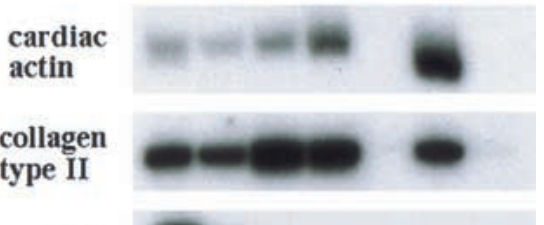

Xnr1

Xnr2

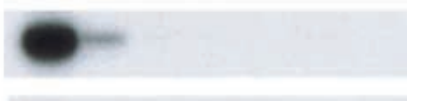

Histone

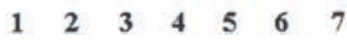

Nodal-related ligands in this assay (Thomson et al. 1990; Jones et al. 1995). Moreover, a constitutively active ALK4 has been reported to induce a partial secondary axis in a similar way as CA-ALK7 (Armes and Smith 1997). To compare the activities of CA-ALK7 and CAALK4 directly, we injected two different doses of each construct into the animal pole and analyzed their ability to induce marker gene expression by RT-PCR in isolated caps (Fig. 1C,D). At gastrulation stages (stage 11), the panmesodermal marker Xbra (Smith et al. 1991), the endodermal transcription factor GATA-4 (Yasuo and Lemaire 1999), and the mesendodermal genes Xnr1 and Xnr2 (Jones et al. 1995) were all induced by CA-ALK4 in a dose-dependent manner, in agreement with previous reports (Yasuo and Lemaire 1999). At this stage, CAALK7 was more effective than CA-ALK4 at inducing GATA-4 but less effective at inducing Xnr1 and $X n r 2$ (Fig. 1C). In contrast, at tailbud stages (stage 20), Xnr1 and Xnr2 expression could only be maintained by CAALK7 and not by CA-ALK4 (Fig. 1D). Of note, the ability of both receptors to induce cardiac actin and Collagen type II expression was comparable at this stage (Fig. 1D). Therefore, although overexpression of either receptor produces a similar phenotype in whole embryos, the results from the ectodermal explant assays suggest that there are qualitative differences between ALK4 and ALK7 in their ability to induce and/or maintain expression of marker genes.

Interestingly, although injection of CA-ALK7 into ventral cells had dorsalizing activity, injection into animal cells leads to a change in fate from ectoderm to endoderm in vivo. Figure 2 shows the results of experiments in which a single animal blastomere was co-injected with CA-ALK7 and LacZ mRNA. Whereas the fate map indicates that these cells will only form ectoderm (Fig. 2A-C), cells expressing CA-ALK7 contributed exclusively to endoderm $(100 \%, n=85)$. This was in agreement with the ability of CA-ALK7 to induce the endodermal markers GATA-4 and XIhbox8 (Fig. 1B,C), and demonstrates that in addition to its ability to induce 

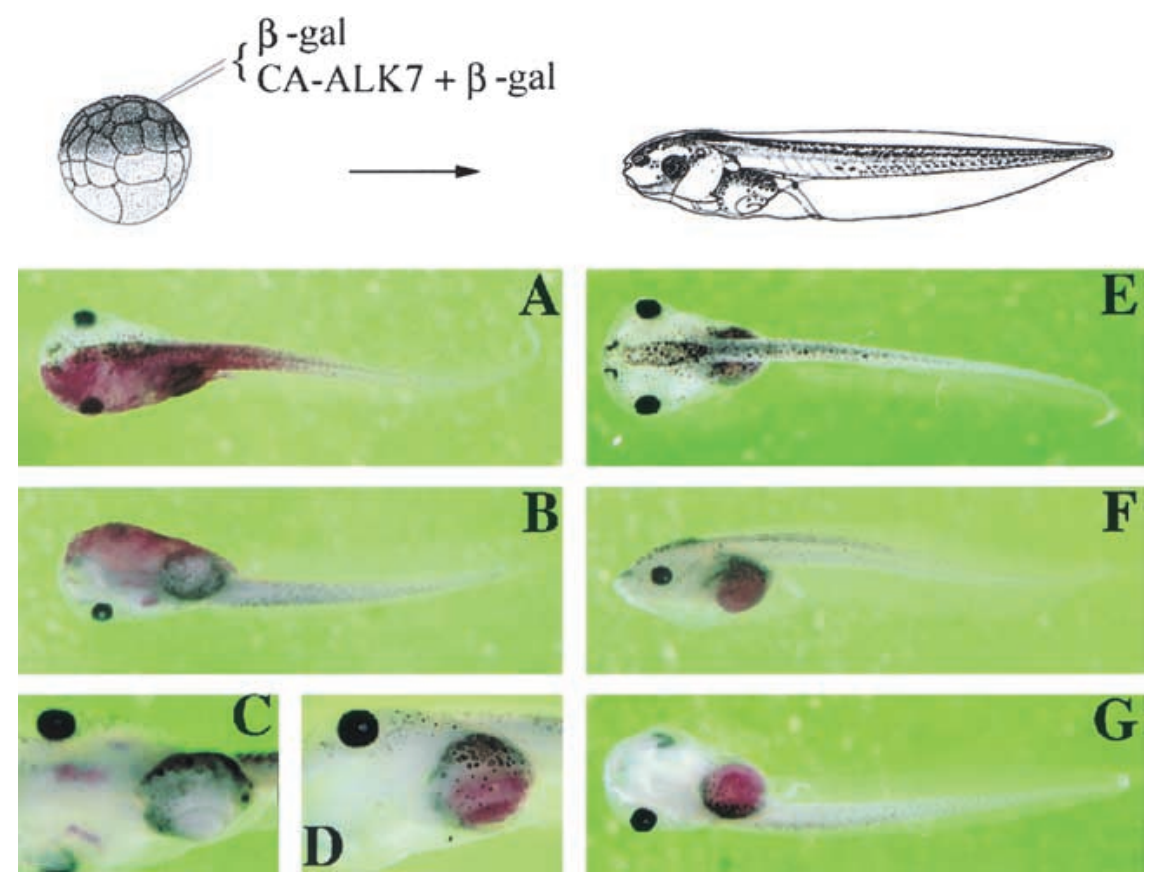

Figure 2. Role of ALK7 in cell fate and cell localization. $(A-C)$ Control embryos injected with LacZ RNA. The $\beta$-gal staining at stage 45 is restricted to skin. $(A)$ Dorsal view. $(B)$ Ventral view. $(C)$ Higher magnification of ventral view with focus on anterior embryonic regions. $(D-G)$ Embryos were co-injected with CA-ALK7 mRNA and LacZ mRNA. The $\beta$-gal staining detects descendants of the injected ectodermal cells specifically localized to the gut, indicating an ectoderm-to-endoderm cell fate transformation and translocation. (D) High magnification with focus on the gut region. $(E)$ Dorsal view. $(F)$ Lateral view. $(G)$ Ventral view. and dorsalize mesoderm, ALK7 signaling can also induce endodermal fates. Similar to CA-ALK7, an activated form of the zebrafish type I receptor TARAM-A converts cells to an endodermal fate (Peyrieras et al. 1998). The sequence similarity between TARAM-A and the activin receptor ALK4 suggests that they act in the same pathway. It is therefore very likely that all receptors activating Smad2 and Smad3, including ALK4, display similar properties in endodermal development. Together, these data demonstrate that ALK7 signaling is sufficient for the induction of both mesoderm and endoderm in vivo.

\section{A dominant-negative ALK7 mutant specifically blocks the activity of Nodal and Xnr1}

Our gain-of-function studies showed that CA-ALK7 mimics the effects of an Activin/Nodal-like signal both in ectodermal explants and in vivo (Thomson et al. 1990; Jones et al. 1995). These experiments, however, could not establish which mesoderm-inducing ligand, if any, may be involved in ALK7 signaling. Previous work has shown that truncated type I receptors lacking an intracellular domain can act as dominant-negative inhibitors of endogenous pathways by forming nonproductive signaling complexes with type II receptors in a ligandspecific manner (Chang et al. 1997; Mahony et al. 1998). We generated a truncated ALK7 receptor construct lacking all intracellular sequences (DN-ALK7), and first examined its effects during normal development after injection of $2 \mathrm{ng}$ DN-ALK7 RNA into the marginal zone of both dorsal blastomeres of four- to eight-cell embryos. Unlike injection of DN-ALK4 (Chang et al. 1997), overexpression of DN-ALK7 did not affect the expression of the pan-mesodermal marker Brachyury at gastrula stages (data not shown). The injected embryos, however, showed severe defects in gastrulation movements, resulting in failure of blastopore closure and spina bifida at tailbud stages ( $82 \%, n=51$; Fig. 3A). Embryos injected in parallel with DN-ALK4 did not display this phenotype, suggesting that the observed defect was specific and not attributable to injection artifacts. The embryos expressing DN-ALK7 showed a perturbed axis and severe decrease of muscle and notochord $(82 \%, n=51)$, although they still retained gut tissue formed in a disorganized way. In addition, we observed a reduction of head structures $(67 \%, n=51)$, including midline fusion of the eyes (Fig. 3A). Interestingly, this embryonic phenotype is very similar to Nodal mutants in mouse and zebrafish (Feldman et al.1998; Nomura and Li 1998).

Next, we tested the ability of DN-ALK7 to inhibit the activities of co-expressed Activin and Nodal-related ligands. It has been shown previously that Xnr1 and Xnr2 are able to induce formation of a partial secondary axis when injected into a ventral vegetal cell at the eight-cell stage (Lustig et al. 1996). Co-injection of DN-ALK7 blocked the ability of Xnr1 to induce a secondary axis, but had no effect on secondary axis induction by Xnr2 (Fig. 3B). Moreover, in ectodermal explants, DN-ALK7 blocked the effects of Xnrl on animal cap elongation but did not affect the activity of Xnr2 in this assay (data not shown). These data suggested an unexpected degree of specificity in the ability of DN-ALK7 to block the activity of Xnr1 over Xnr2, despite the close sequence similarity between these two ligands.

As reported previously (Weeks and Melton 1987; Thomson et al. 1990; Jones et al. 1995), Xnr1, Xnr2, Xnr4, and Activin promoted mesoderm induction in animal cap explants as demonstrated by the expression of cell type-specific markers (Fig. 4A). Co-injection of DNALK7 selectively inhibited the effects of Xnr-1 on meso- 
A
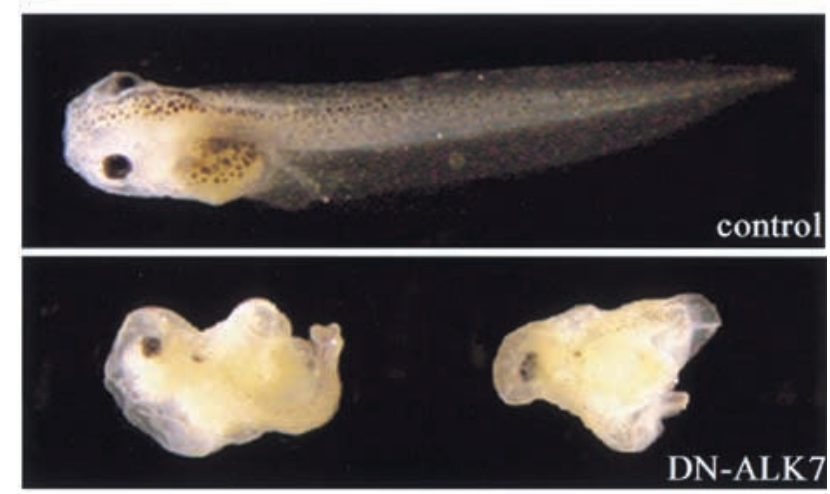

B
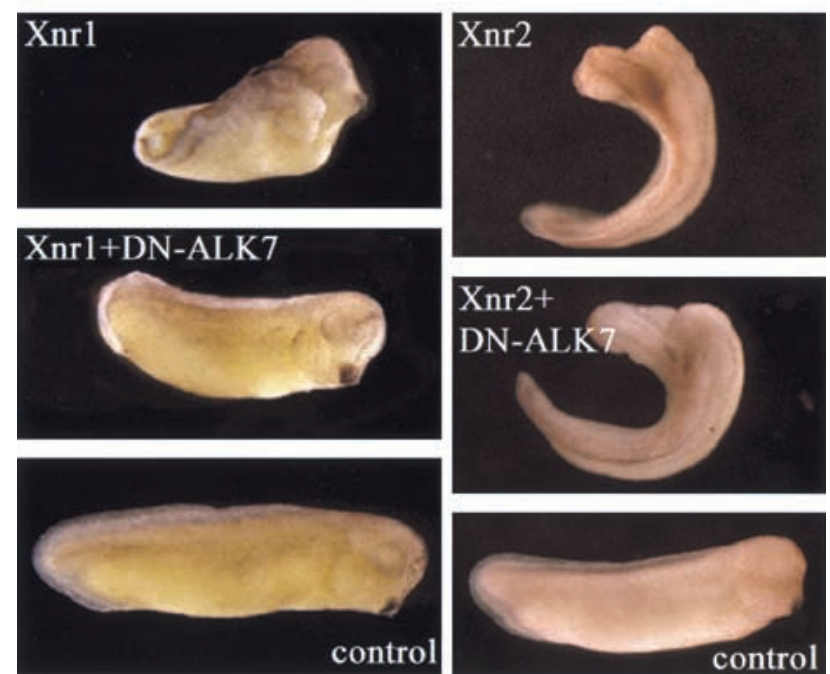

$\mathrm{Xnr} 2+$ DN-ALK7
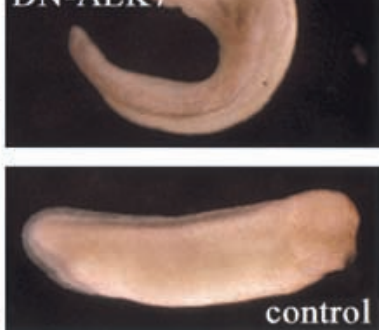

Figure 3. Dominant-negative ALK7 (DN-ALK7) produces anterior defects and cyclopia, and inhibits Xnrl activity in ectodermal explants and in whole embryos. (A) Embryonic phenotype of DN-ALK7 overexpression in vivo. Injection of $2 \mathrm{ng} \mathrm{DN}$ ALK7 into all four marginal cells at the eight-cell stage resulted in anterior head defects, including cyclopia, and axial truncations (19\% and $87 \%$ respectively, $n=46)$. Control sibling at late tadpole stage. Anterior to the left. (B) DN-ALK7 inhibits the formation of a partial secondary axis by Xnrl. Injection of $1 \mathrm{ng}$ Xnr1 or Xnr2 RNA into one ventral-vegetal cell at the eight-cell stage resulted in a partial secondary axis $(62 \%$, total $n=32$; $54 \%$, total $n=22$, respectively). Co-injection of $4 \mathrm{ng}$ DN-ALK7 RNA inhibited the Xnrl-mediated phenotype (92\%, total $n=28$ ), whereas Xnr2 activity was unaffected. A sibling control embryo (stage 28) is shown in the bottom panels.

derm induction as determined by RT-PCR analysis at stage 25 (Fig. 4A, late) and stage 11 (Fig. 4A, early). In contrast, coinjection of DN-ALK7 had no effect on the ability of Xnr2, Xnr4, or Activin to induce expression of mesodermal markers (Fig. 4A). On its own, DN-ALK7 was unable to induce expression of any marker in ectodermal explants (Fig. 4A). We also compared the ligand specificities of ALK7 and ALK4 in the animal cap assay (i.e., induction of cardiac actin) using dominant-negative constructs of each receptor together with different doses of mouse Nodal, Xnr1, Xnr2, Xnr4, and Activin tested over a 20-fold concentration range. All ligands were blocked by DN-ALK4 (Fig. 4B), indicating that this truncated receptor interferes with signaling by a variety of related proteins in the Activin/Nodal subfamilies. In contrast, DN-ALK7 preferentially blocked the activities of Xnr1 and mouse Nodal (Fig. 4B). Xnr2 was only inhibited at the lowest concentration tested, whereas the ac-

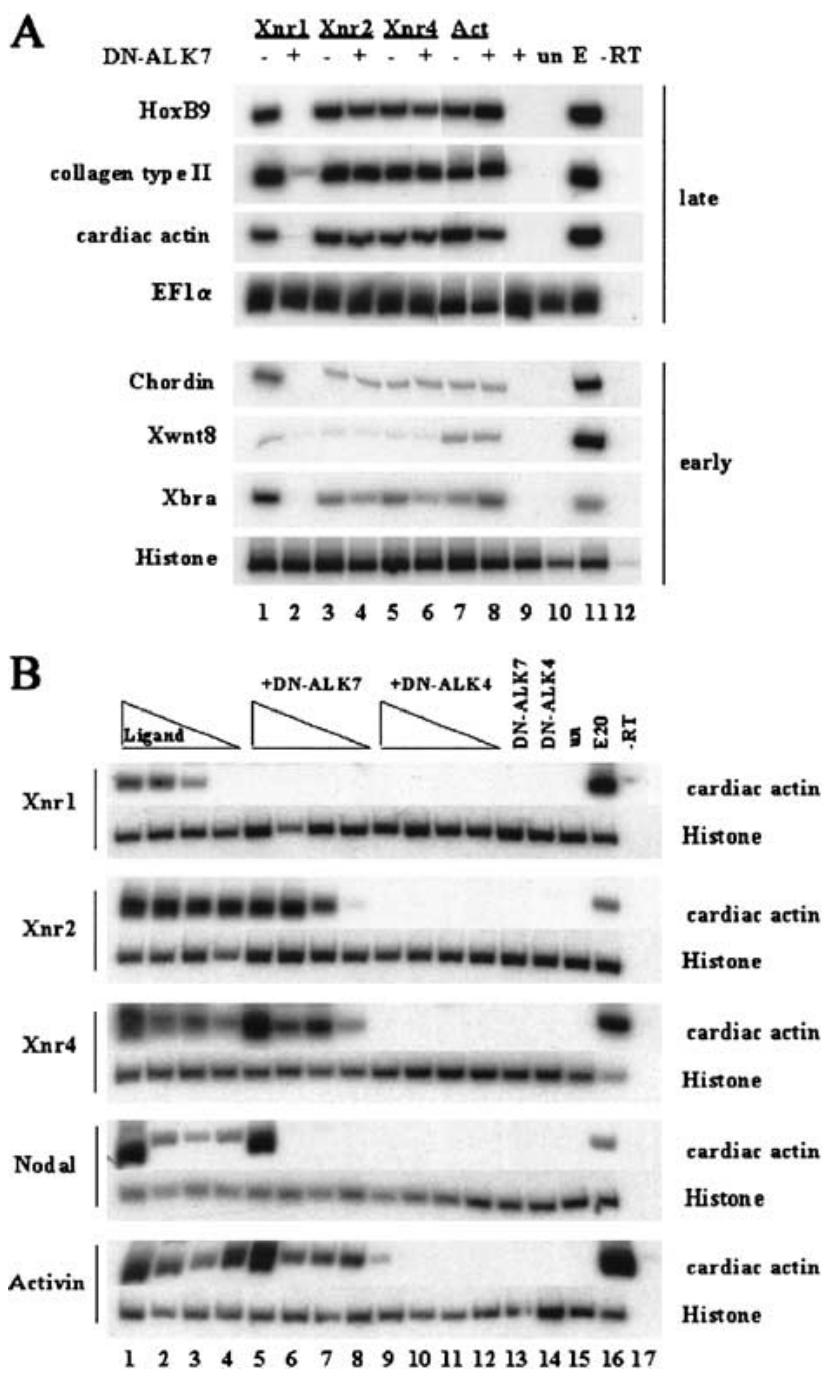

Figure 4. DN-ALK7 and DN-ALK4 inhibit mesoderm formation induced by Xnr1 and Nodal, whereas the activities of Xnr2, Xnr4, and Activin are only efficiently inhibited by DN-ALK4. (A) DN-ALK7 inhibits late and early mesodermal marker gene expression induced by Xnr1. DN-ALK7 alone did not induce any marker genes (lane 9). (un) Uninjected explants; (E) whole embryo control; $(-\mathrm{RT})$ no reverse transcriptase. Stage 25 (late) and stage 11 (early) were analyzed. (B) Dose-response analysis of mesoderm-inducing ligand activity in the absence or presence of DN-ALK7 and DN-ALK4. (Lanes 1-4) Ligand (RNA concentrations for Xnr1, Xnr2, Xnr4, and Nodal were $1 \mathrm{ng}, 0.5 \mathrm{ng}, 0.1 \mathrm{ng}$, and $0.05 \mathrm{ng}$, respectively; RNA concentrations for Activin were $10 \mathrm{pg}, 5 \mathrm{pg}, 1 \mathrm{pg}$, and $0.5 \mathrm{pg}$, respectively); (lanes 5-8) ligands in the presence of 2 ng DN-ALK7; (lanes 9-12) ligands in the presence of 2 ng DN-ALK4; (lanes 13,14) DN-receptors alone. 
tivities of Xnr4 and Activin were unaffected (Fig. 4B). Together, these results demonstrate that, when compared with DN-ALK4, DN-ALK7 appears to more specifically block the activities of Xnr1 and Nodal over other members of the Activin/Nodal subfamily.

\section{ALK7 and ActRIIB collaborate to form a functional receptor complex for Xnr1 and Nodal}

The ability of DN-ALK7 to block the activity of Xnr1 and Nodal suggested that ALK7 might be a receptor for these ligands. To test this hypothesis directly, we first attempted to reconstitute a functional receptor complex in heterologous cells. To identify which of the known type II receptors might serve as a partner for ALK7 signaling, we took advantage of the ability of type II receptors to transactivate their cognate type I receptor when overexpressed, even in the absence of ligand. To monitor receptor activity, we used a reporter plasmid construct consisting of nine tandem copies of the Smad-binding element (CAGA) from the Plasminogen Activator Inhibitor-1 (PAI-1) gene promoter upstream of a luciferase reporter gene (Dennler et al. 1998). On transfection in the human hepatoma cell line HepG2, CA-ALK7, but not wild-type ALK7, greatly stimulated luciferase activity from this reporter construct (Fig. 5A). In dose-response experiments, wild-type ALK7 was found to specifically synergize with ActRIIB, but not with other type II receptors, including BMPRII and the highly related receptor ActRIIA (Fig. 5A). We then used sub-saturating doses of ALK7 and ActRIIB plasmid DNAs either alone or in combination, and tested responsiveness to $\mathrm{Xnrl}$ and mouse Nodal. Control HepG2 cells, or cells transfected with either ALK7 or ActRIIB alone, did not respond to Xnr1 or to Nodal (Fig. 5B). Coexpression of ALK7 and ActRIIB, however, conferred responsiveness to both Xnrl and Nodal in a dose-dependent manner (Fig. 5B), indicating that both molecules are required to form a functional receptor for these ligands.

We also tested the ability of ALK4 to mediate responses to Xnrl and Nodal in this assay. In contrast to ALK7, ALK4 was not able to confer responsiveness to Nodal proteins in HepG2 cells in combination with ActRIIB (Fig. 5C). This combination of receptors, however, mediated a robust response to Activin (Fig. 5C). Overexpression of ALK7 together with ActRIIB did not increase the responsiveness of HepG2 cells to Activin (data not shown), which is consistent with the inability of ALK7 to bind this ligand (Rydén et al. 1996). Together, these results indicate that ALK7, but not ALK4, is sufficient, together with ActRIIB, to confer responsiveness to Xnrl and mouse Nodal in heterologous cells.

The EGF-CFC protein Cripto potentiates ALK7 signaling by Nodal proteins and allows ALK4 to mediate responses to Xnr1 and Nodal

The inability of ALK4 to mediate Nodal responses in HepG2 cells contrasted with its postulated role in Nodal signaling based on genetic experiments (Gu et al. 1998), and with the ability of DN-ALK4 to block the activity of Nodal-related ligands in animal cap explants (see Fig. 4). As explained above, members of the EGF-CFC family have been proposed as necessary co-factors for signaling by Nodal and related ligands (Shen and Schier 2000). These proteins are anchored to the plasma membrane by a GPI link and therefore lack an intracellular domain, suggesting a role for EGF-CFC proteins as ligand-binding co-factors requiring transmembrane partner receptors for signal transduction (Gritsman et al. 1999). When introduced in HepG2 cells, the mouse EGF-CFC protein Cripto greatly potentiated the response to Xnrl and Nodal mediated by ALK7 and ActRIIB (Fig. 5D left, cf. with B). Moreover, in the presence of Cripto, ALK4 was able to mediate robust responses to Xnrl and Nodal together with ActRIIB (Fig. 5, cf. D right with C). These results suggest that Cripto potentiates responses to Nodal ligands mediated by ALK7 and ALK4, but that only the latter receptor has an absolute requirement for Cripto to mediate signal transduction by Nodal and related factors.

ALK7, ActRIIB, and Cripto can bind Xnr1 directly, whereas ALK4 and ALK7 can associate with Cripto

Next, we investigated biochemical interactions between Nodal-related proteins and receptors in co-precipitation assays. Immunoglobulin-tagged ALK7 ectodomain (ALK7-Fc) was able to specifically precipitate radiolabeled mature Xnrl protein from the conditioned medium of microinjected oocytes (Fig. 6A). No significant binding of ALK7-Fc to Activin could be detected over background under similar conditions (Fig. 6A). In addition, purified ActRIIB-Fc, but not a control Fc fusion protein, was able to precipitate hemagglutinin (HA)-tagged Xnr1 produced in COS cells (Fig. 6B). In agreement with its requirement of Cripto for Nodal signaling, ALK4-Fc and Cripto could associate directly in the absence of ligand (Fig. 6C,D). ActRIIB-Fc did not interact with Cripto (Fig. 6C). ALK7-Fc was also able to bind Cripto (Fig. 6E). Moreover, purified Cripto was very efficient at precipitating HA-tagged Xnr1 from COS cell-conditioned medium (Fig. 6F). Therefore, ALK7, ActRIIB, and Cripto are all able to bind Xnr1. On the other hand, ALK4 and ALK7 are able to associate with Cripto directly, suggesting a mechanism of cooperation between these receptors in Nodal signaling.

\section{ALK7 mRNA is localized to the ectodermal and organizer regions of Xenopus gastrula embryos and is expressed during early stages of mouse embryonic development}

To investigate the endogenous pattern of expression of ALK7 during Xenopus embryonic development, we isolated a fragment of the Xenopus ALK7 gene by degenerate PCR amplification of genomic sequences (see Materials and Methods). This strategy yielded a 164-bp nucleotide fragment highly homologous to rat $A L K 7$ 
Reissmann et al.

Figure 5. Reconstitution of functional receptors for Xnr1 and Nodal in heterologous cells. (A) Transactivation of ALK7 by overexpression of ActRIIB, but not ActRIIA or BMPRII, in HepG2 cells. The dose of CA- or wild-type (wt) ALK7 plasmid DNA was $1 \mathrm{ng}$ per three wells. Type II receptors were transfected at $0.1,0.3,1$, and $3 \mathrm{ng}$ per three wells. (B) ALK7 and ActRIIB confer responsiveness to Xnrl (left) and mouse Nodal (right) in heterologous cells. Ligand DNAs were transfected at the indicated amounts (per three wells). Results are expressed as mean $\pm S D$, and are representative of three independent experiments. $(C)$ ALK4 and ActRIIB do not suffice to confer responsiveness to Xnrl and Nodal. HepG2 cells were transfected with ALK4, ActRIIB, and the indicated ligands. Results are expressed as mean \pm $\mathrm{SD}$, and are representative of three independent experiments. $(D)$ Cripto enhances the response of ALK7 to Nodal proteins and allows Nodal and Xnrl signaling via ALK4. HepG2 cells were transfected with receptors and ligands as indicated. In the absence of transfected ALK4 or ALK7 receptors, Cripto produced a much smaller response to Xnrl and Nodal (Cripto alone), in agreement with the presence of low levels of endogenous Activin receptors in HepG2 cells. Results are expressed as mean $\pm S D$, and are representative of three independent experiments.
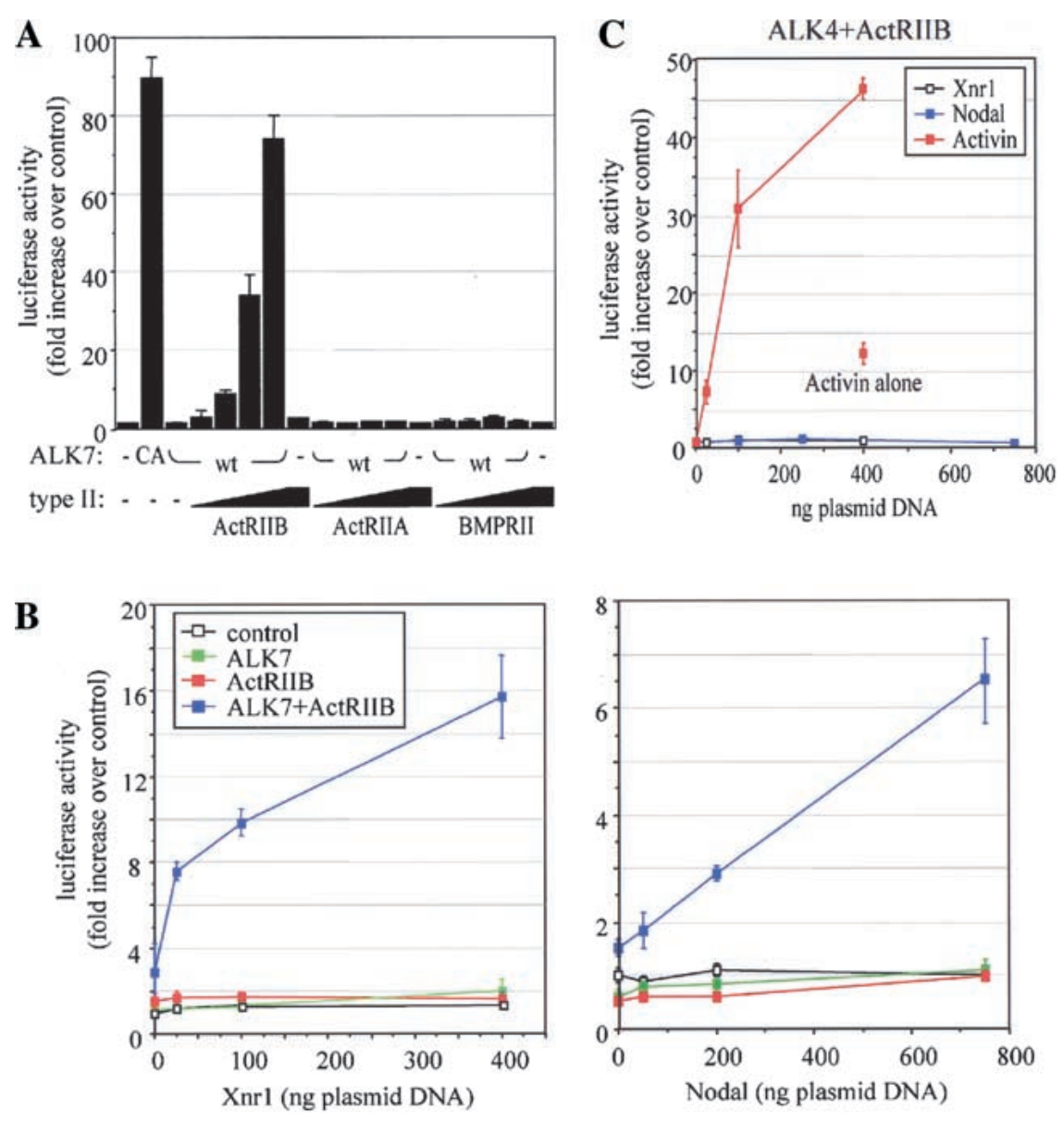

D

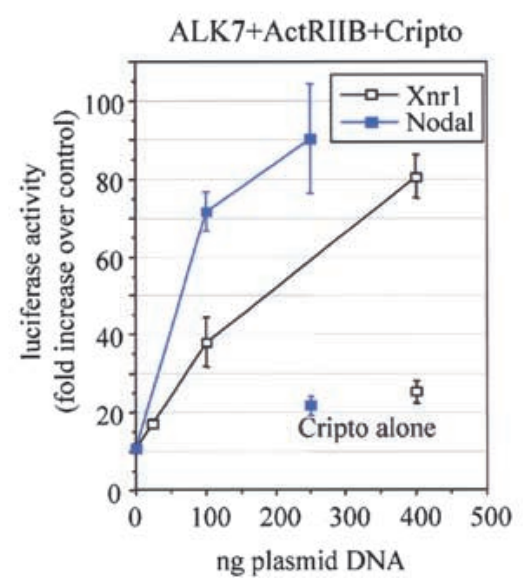

(Fig. 7A). Phylogenetic analysis of this sequence together with homologous regions from rat and Xenopus ALK4 and $A L K 5$, the two type I receptors most related to $A L K 7$, showed that the isolated sequence was indeed more similar to mammalian $A L K 7$ than to any other type I receptor subtype (Fig. 7B), indicating that we had isolated a fragment of the Xenopus ALK7 gene.

Based on this sequence, we designed primers for RTPCR experiments that specifically amplified Xenopus ALK7 (xALK7) but not $x A L K 4$ or $x A L K 5$ (data not shown). The RT-PCR analysis showed that expression of $x A L K 7$ was present maternally at low levels, increased at gastrula stages, and continued through tadpole stages (Fig. 7C). At gastrula stage (stage 10.5), xALK7 expression was detected in the dorsal marginal zone and the animal pole region as determined by RT-PCR and in situ hybridization (Fig. 7D,E). The expression of $A L K 7$ in these regions of the developing Xenopus embryo is in agreement with a role in mediating Xnrl signaling in vivo (Jones et al. 1995). 
A

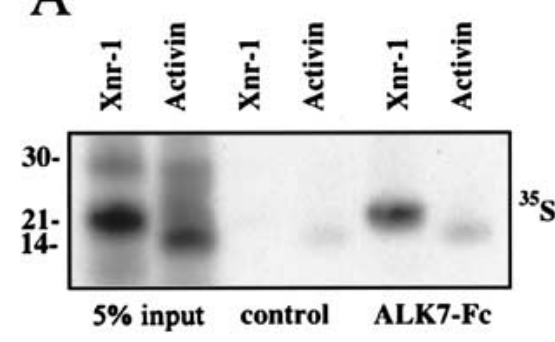

$\mathrm{C}$

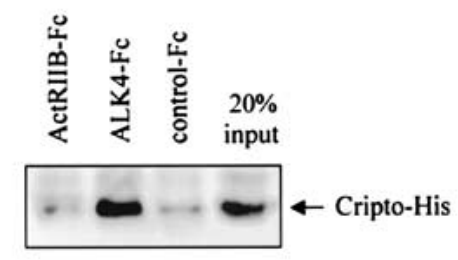

immunoblot: anti-His

E

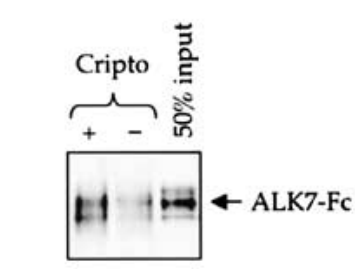

immunoblot : anti Fc
B

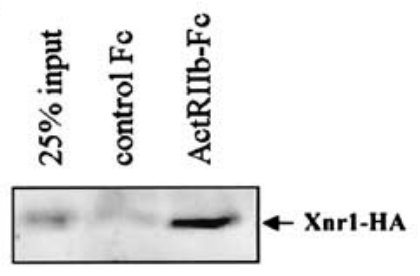

immunoblot : anti HA
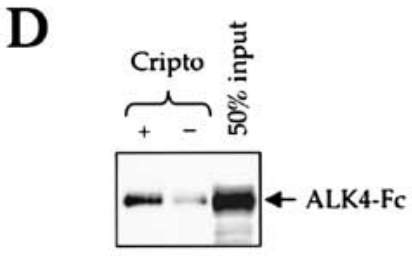

immunoblot : anti Fc

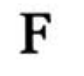

Cripto-His:

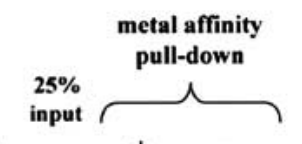

Xnr1-HA:

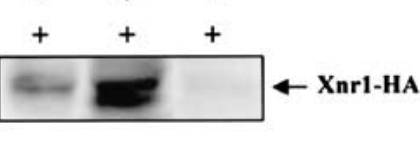

Figure 6. ALK7, ActRIIB, and Cripto can bind Xnrl directly, whereas ALK4 and ALK7 can associate with Cripto. (A) Binding of Xnrl to soluble ALK7-Fc. Residual Activin signal in the ALK7-Fc lane is comparable with control, indicating background binding. (B) Binding of Xnrl to soluble ActRIIB-Fc. As control, a purified GFR $\alpha 1-F c$ fusion was used (control Fc). (GFR $\alpha 1$ stands for glial cell line-derived neurotrophic factor (GDNF) family receptor $\alpha-1)$. (C) Cripto associates with ALK4 in the absence of ligand. Following precipitation with Protein-G beads, Cripto was detected by immunoblotting with anti-Histidine antibodies. Comparable amounts of Fc fusion proteins were used as determined by re-probing with anti-human IgG antibodies. $(D)$ Reverse pull-down of ALK4-Fc and Cripto. Following precipitation with metal-affinity beads, ALK4-Fc was detected by immunoblotting with anti Fc antibodies. (E) Cripto associates with ALK7. Co-precipitation assay showing binding of purified ALK7-Fc to purified His-tagged Cripto. Following precipitation with metal-affinity beads, ALK7-Fc was detected by immunoblotting with anti-Fc antibodies. $(F)$ Cripto binds Xnrl directly. Co-precipitation assay showing binding of HA-tagged Xnrl produced in COS cells to purified His-tagged Cripto. Following precipitation with metal-affinity beads, Xnrl was detected by immunoblotting with anti-HA antibodies.

Finally, because $A L K 7$ mRNA expression has so far been reported in postnatal stages of rat development, we investigated expression of $A L K 7$ in early stages of mouse embryonic development by RNase protection assay (RPA). Using a riboprobe specific for mouse ALK7 sequences, ALK7 mRNA expression could be detected from embryonic day 7 (E7) in the mouse (Fig. 7F), indicating that $A L K 7$ is expressed in gastrulating mouse embryos.

\section{Discussion}

\section{ALK4 and ALK7 are functional receptors for Nodal and the Nodal-related protein Xnr1}

TGF- $\beta$ superfamily ligands and receptors are highly conserved during metazoan evolution, and can be functionally substituted between species even as distantly related as human and Drosophila (Kingsley 1994; Chang et al. 1997). We have taken advantage of this high conservation to investigate the function of ALK7 during Xenopus development using the rat homolog of this receptor for embryological and biochemical studies. Overexpression of the constitutively active mutant receptor CAALK7 resulted in mesendodermal induction and formation of a partial secondary axis similar to overexpression of a constitutively active form of the Activin receptor ALK4 (Armes and Smith 1997; Chang et al. 1997). Despite these similarities, we were able to detect functional differences between these two type I receptors. At gas- trula stages, CA-ALK7 is less effective at inducing Xnr1 than CA-ALK4. At tailbud stages, however, only CAALK7 seems to be able to maintain $X n r$ gene expression, indicating a late role in Nodal signaling for this receptor component. Together with results from other recent studies (Jörnvall et al. 2001), these observations indicate that highly related, albeit distinct, type I serine/threonine kinase receptors have the capacity to elicit different biological responses.

In addition to gain-of-function studies, the loss-offunction assays with dominant-negative receptors also indicated that ALK7 and ALK4 have distinct functions during early embryogenesis. DN-ALK4 has been shown to inhibit the pan-mesodermal marker Brachyury expression at gastrula stages and to completely block axis formation of tailbud embryos, resulting in formation of "bubble embryos." DN-ALK7, on the other hand, was not efficient at inhibition of early Brachyury transcription and did not eliminate all axial structures, such as muscle, but it did cause a profound gastrulation movement defect. In agreement with these observations, DNALK7 specifically blocked the activities of Nodal and Xnr1 but had little effect on other related ligands, whereas dominant-negative ALK4 blocked all mesoderm-inducing ligands tested including Nodal, Xnr1, Xnr2, Xnr4, and Activin. Unlike ALK4, ALK7 cannot be activated by Activin (Rydén et al. 1996), and could be activated by Xnrl and Nodal in the absence of Cripto. Because ALK4 was found to interact with Cripto directly in the absence of added ligand, it remains unclear 
Reissmann et al.
A xALK7 :
DNGTWTQLWLISEEFHEQGSLFDYLNRNTVTIGGMMKLALS IVSGLAHLHME IVG
rALK7 :
$+-$
$+$
$-+-+$

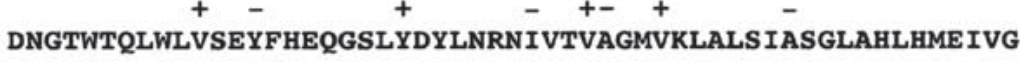
(259-312aa)

B

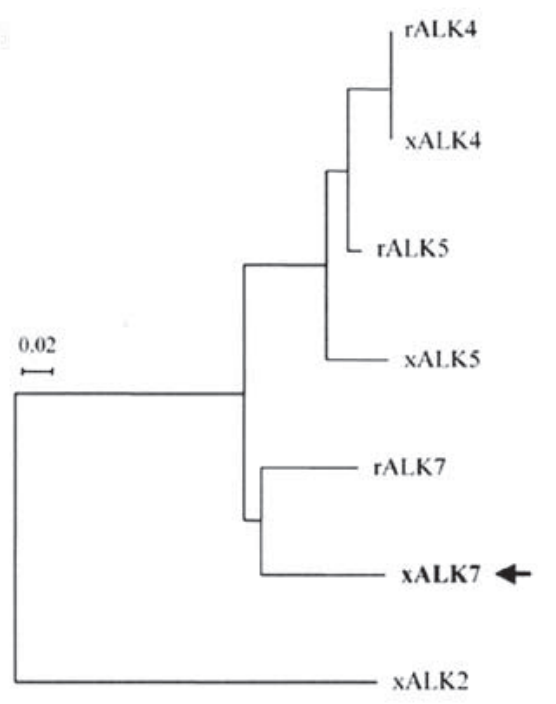

D

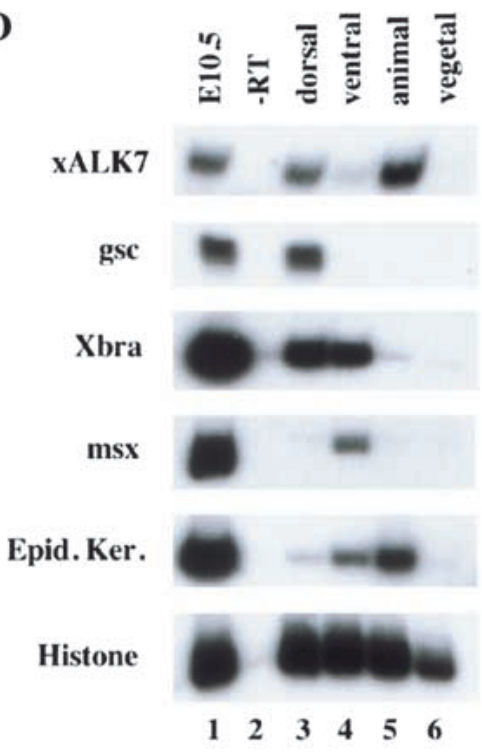

C

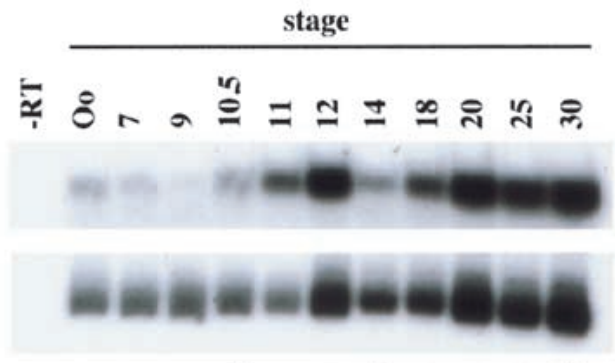

$\begin{array}{llllllllllll}1 & 2 & 3 & 4 & 5 & 6 & 7 & 8 & 9 & 10 & 11 & 12\end{array}$

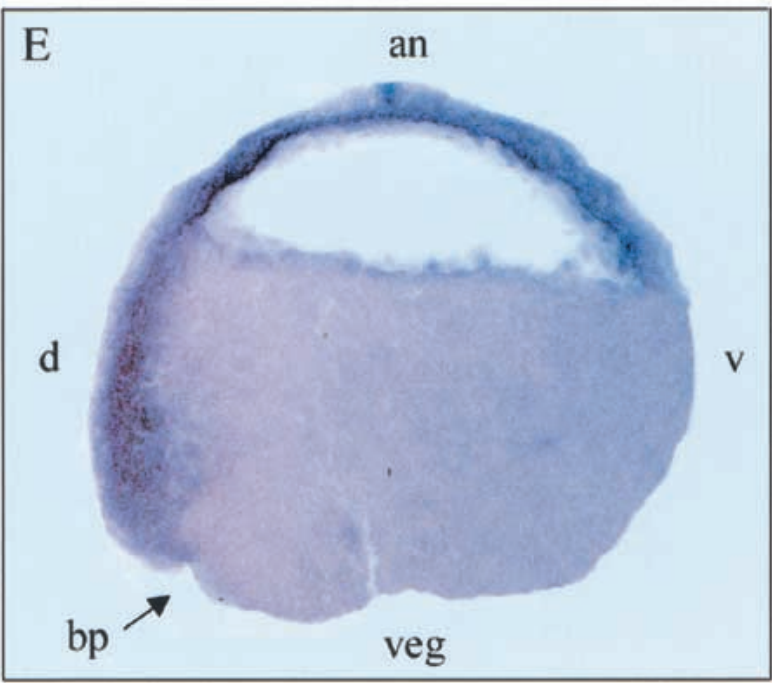

$\mathbf{F}$

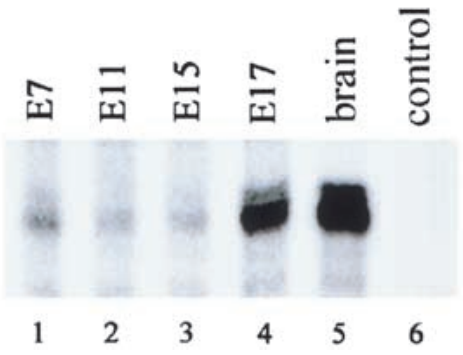

Figure 7. ALK7 mRNA is localized in the ectodermal and organizer regions of Xenopus gastrula embryos and is expressed during early stages of mouse embryonic development. (A) Amino acid sequence alignment of Xenopus and rat ALK7 fragments. The Xenopus ALK7 fragment obtained overlaps with the rat sequence from amino acid residues 259 to 312 located to the kinase domain. (+) Conservative changes; (-) non-conservative changes. (B) Phylogenetic analysis of homologous fragments from Xenopus and rat ALK7, and the related receptors ALK4 and ALK5. The tree was drawn using NJPLOT based on an alignment made in CLUSTALX. (C) Xenopus ALK7 is expressed maternally and persists throughout development as analyzed by RT-PCR on oocytes and embryos. (D) Expression of xALK7 is localized to dorsal-animal regions in early gastrula stage embryos. As control for correct embryo dissection the following marker genes were used: (Gsc) goosecoid (dorsal expression); (Xbra) Brachyury (dorsal-ventral or marginal); (msx) muscle-segment-homeoboxrelated gene (ventral); (EK) epidermal keratin (animal-ventral). Histone was used as loading control. (E) In situ hybridization analysis reveals expression of ALK7 in the organizer. Cross sections of those embryos show ALK7 expression in dorsal (d) and animal pole region (an). The blastopore lip (bp) is indicated. (v) Ventral; (veg) vegetal. (F) Expression of ALK7 mRNA in the early mouse embryo. RNA from the indicated days of mouse embryonic development (lanes 1-4), as well as adult brain mRNA (lane 5) and negative control (yeast tRNA, lane 6) were analyzed by RNase protection assay (RPA) for expression of $A L K 7$ mRNA using a specific mouse $A L K 7$ riboprobe.

whether ALK4 also makes direct contacts with Xnr1 in the complex. Together, these data support a more spe- cific role for ALK7 in mediating the activity of Xnr1 and Nodal over other Activin-like ligands, and suggest that 
ALK7 may have a higher affinity for Nodal ligands than ALK4.

Our results also demonstrate that ALK7 collaborates with ActRIIB, but not with the closely related ActRIIA, to generate a functional receptor complex for Xnrl and Nodal. This observation is consistent with previous results regarding the role of type II Activin receptors in Xenopus (Hemmati-Brivanlou et al. 1992; Mathews et al. 1992; Nishimatsu et al. 1992a,b; New et al. 1997). Genetic evidence from mice also supports a role for ActRIIB in Nodal signaling. Mice lacking ActRIIB have defects in left-right axis formation, a characteristic Nodal activity. Interestingly, although the ActRIIA knockout has no early embryonic phenotype (Matzuk et al. 1995b), the double knockout of ActRIIA and ActRIIB shows several deficits similar to Nodal loss-of-function, including cyclopia, anterior neuronal truncation, and lack of primitive streak, mesoderm and endoderm (Song et al. 1999).

Although only one Nodal gene is known in mouse and chick, several Nodal-related homologs have been found in Xenopus and zebrafish. In Xenopus, Xnr1 to Xnr6 have very similar expression patterns in early development, and all factors are capable of inducing mesendoderm (Sampath et al. 1997; Osada and Wright 1999; Takahashi et al. 2000), although with different potency. At later stages of development, Xnr1 and Xnr4 are expressed in different regions (Lowe et al. 1996; Lustig et al. 1996; Joseph and Melton 1997), and Xnr1 has a unique role in left-right patterning that cannot be substituted by any of the other Xnr ligands (Capdevila et al. 2000). In zebrafish, two Nodal-related genes, squint and cyclops, also show complementary functions (Hatta et al. 1991; Thisse et al. 1994; Heisenberg and Nuesslein-Vollhardt 1997; Sampath et al. 1998). This diversity of functions of Nodalrelated proteins could reflect cell type-specific responses or, alternatively, the existence of distinct receptors for different Nodal-related ligands. The fact that DN-ALK7 could only block the activity of mouse Nodal and Xenopus Xnrl suggests the existence of additional receptors with specificity for other Nodal family members.

In contrast to the ubiquitous expression of ALK4 in the gastrulating Xenopus embryo (Chang et al. 1997), endogenous expression of ALK7 was found localized to the organizer, a position overlapping with that of Nodalrelated ligands (Jones et al. 1995; Smith et al. 1995; Joseph and Melton 1997; Takahashi et al. 2000). Therefore, ALK7 is the first type I receptor with a localized expression in the early Xenopus embryo. Similar to ALK4, the Xenopus Cripto homolog FRL-1 is also expressed in gastrula embryos, but is not localized to any particular region (Kinoshita et al. 1995). ALK7 was also detected in the animal pole, a tissue that does not express, but is responsive to, Nodal-related proteins (this study; see also Jones et al. 1995). The identity of the endogenous ligands that use ALK7 in the animal pole is, however, unclear. Our finding of $A L K 7$ mRNA expression in gastrula stages of the mouse embryo is in agreement with a role for this receptor in Nodal signaling in the mouse. The expression of $A L K 7$ in different adult brain structures, notably the cerebellum (Rydén et al. 1996; Tsuchida et al. 1996), suggest possible activities of Nodal proteins in postmitotic neurons.

\section{EGF-CFC proteins and Nodal signaling}

Loss of EGF-CFC factors, such as the zebrafish one-eyed pinhead and the mouse Cripto and Cryptic, results in a phenotype comparable with loss of Nodal, and several studies indicated that they are essential for Nodal signaling (Gritsman et al. 1999). The fact that EGF-CFC proteins are tethered to the plasma membrane by a GPI link, and therefore lack a cytoplasmic domain, indicated a proximal role in the Nodal signaling cascade, either as ligand-binding components of the Nodal receptor complex or as modulators of the cellular response to Nodal. Our results showing a direct interaction between Cripto and Xnrl support the first possibility and suggest that EGF-CFC proteins participate directly in the reception of the Nodal signal at the plasma membrane. The ability of Cripto to interact with ALK4 and ALK7, but not with ActRIIB, suggests that EGF-CFC proteins target type I, not type II, receptors in the complex. The fact that ALK7, unlike ALK4, did not require Cripto for responsiveness to $\mathrm{Xnrl}$ is in agreement with the ability of this receptor to directly interact with this ligand. Nevertheless, Cripto was still able to greatly potentiate (by 5- to 15fold) the responsiveness of the ALK7/ActRIIB receptor complex to Xnr1 and Nodal, indicating that both ALK7 and ALK4 collaborate with Cripto and perhaps other EGF-CFC proteins for efficient responsiveness to Nodal ligands.

In conclusion, our results indicate that the receptor ALK7 and the Activin receptor ALK4 can act as a type I receptors for Nodal and related ligands together with ActRIIB and the GPI-anchored protein Cripto. Further studies on these receptors, including the generation and analysis of mice deficient in ALK7 expression, will contribute to clarify the different mechanisms of extracellular regulation of Nodal signaling during development.

\section{Materials and methods}

Cloning of Xenopus ALK7 and generation

of receptor constructs

Degenerate oligonucleotides, 5'-GAY AAY GGI ACI TGG ACN CAR-3'; and 5'-GTI CCI ACD ATY TCC ATR TG-3', corresponding to peptide sequences DNGTWTQ and HMEIVG within the kinase domain of rat ALK7 were used to amplify $\mathrm{x} A L K 7$ from genomic Xenopus laevis DNA. Site-directed mutagenesis was performed as described (Kunkel 1985).

Embryos, RNA preparation, microinjection, and ectodermal explants

Xenopus laevis embryos were obtained and staged as described (Hemmati-Brivanlou et al. 1992). Embryonic stages were determined as described in Nieuwkoop and Faber (1967). Capped RNA was generated using the Message Machine Kit (Ambion) according to manufacturer's instructions. Animal cap assays were performed by injection of mRNA at two-cell stage into the 
animal pole and explantation at blastula stage (stages 8-9). Total RNA was extracted from the animal caps at indicated sibling stage and RT-PCR was performed to assay for specific marker gene expression (Chang et al. 1997). The embryos were fixed in formaldehyde solution (MEMFA) at the indicated stages followed by $\beta$-gal staining (Chang et al. 1997).

\section{RT-PCR assay}

RT-PCR analysis was performed as described (Chang et al. 1997). Primers for marker genes are published as following: EF1 $\alpha$, cardiac actin, Xbra, and NCAM (Hemmati-Brivanlou and Melton 1994); Xlhbox8 and collagen type II (Lemaire et al. 1998); hoxb9 (Wright et al. 1990); Xwnt8 (Heasman et al. 1994); GATA-4, Xnr1, and Xnr2 (Yasuo and Lemaire 1999); and Chordin (Sasai et al. 1994). Primers for detection of $X A L K 7$ are as follows: sense: $5^{\prime}$-GCT TAT TTC AGA ATT CCA TGA ACA GG-3' and antisense: 5' -CCG ACA ATC TCC ATG TGT AGG TGC-3'. PCR conditions were as follows: $30 \mathrm{~min}$ at $90^{\circ} \mathrm{C}, 1 \mathrm{~h}$ at $50^{\circ} \mathrm{C}, 30 \mathrm{~min}$ at $70^{\circ} \mathrm{C}$ for 21 or 25 cycles.

\section{Whole-mount in situ hybridization and sectioning}

Xenopus ALK7 antisense probe was synthesized with T7 RNA polymerase after linearization with EcoRI. Before in situ hybridization, embryos were embedded in $20 \%$ gelatin and sectioned using a vibratom $(100 \mu \mathrm{m})$. In situ hybridization was then performed on individual sections using the protocol described by Chang et al. (1997).

\section{RNase protection assay}

Mouse embryo total RNA was obtained from Clontech. For RNase protection assays, a 324-bp HindIII-BmrI fragment of the mouse ALK7 cDNA (AA794241) was used as template for RNA polymerization. A rat glyceraldehyde-3-phosphate dehydrogenase $(G A P D H)$ riboprobe was used for normalization. Total RNA $(50 \mu \mathrm{g})$ was hybridized to $\left[\alpha{ }^{32} \mathrm{P}\right] \mathrm{CTP}$-labeled cRNA probes using a kit from Ambion according to the manufacturer's instructions. Protected bands were visualized and quantified using a STORM840 phosphorimager and ImageQuant software (Molecular Dynamics).

\section{Production of proteins and binding assays}

Oocytes were obtained and cultured as described /Chang and Hemmati-Brivanlou 1999). Radiolabeled Xnrl and Activin were recovered from supernatants of oocytes injected with $40 \mathrm{ng}$ of RNA and incubated for $3 \mathrm{~d}$ in $25 \mu \mathrm{L}$ per oocyte of OR 2 medium containing ${ }^{35}$ S-Methionine. The biological activity of radiolabeled ligands was tested by their ability to induce mesodermal markers in animal caps. For pull-down assays, hemagglutinin (HA)-tagged Xnr1 and ALK7-Fc were produced in supernatants of transiently transfected COS cells. Expression of receptor-Fc fusion protein was assayed by Western blot analysis using an anti-human Fc-antibody (Jackson Immuno Research) followed by ECL detection (Amersham Pharmacia Biotech). Recombinant Cripto protein was produced in 293 cells as a Histidinetagged fusion protein lacking Cripto amino acid residues +156 to +172 and purified from the conditioned medium by metal chromatography. ActRIIB-Fc and ALK4-Fc were obtained from R\&D Systems.

Receptors (ALK7-Fc or ALK4-Fc) and radioactive labeled ligands (Xnr1/Activin) were pre-incubated for $2 \mathrm{~h}$ on ice before addition of Protein-G Sepharose beads in Tris Buffer Saline containing Tween-20 (TBST) and $0.1 \%$ BSA for $2 \mathrm{~h}$ at $4^{\circ} \mathrm{C}$. After washing, protein complexes were analyzed by SDS-PAGE and autoradiography. Co-precipitation of Xnr1-HA with ActRIIB-Fc was performed essentially as above, except that Xnr1-HA was detected by Western blotting using an anti-HA monoclonal antibody (Covance). TALON metal-affinity beads (Clontech) were used for precipitation of Xnr1-HA with Cripto-His, followed by Western blotting with anti-HA antibodies. For detection of Cripto-His by immunoblotting, we used anti-poly-His antibodies from Invitrogen.

\section{Luciferase reporter assays}

For luciferase reporter assays, HepG2 cells were cultured in 24well plates and transfected with plasmid DNA using Fugene-6 (Roche). To control for cell number and transfection efficiency, Renilla luciferase under a minimal cytomegalovirus promoter (pRL-CMV, Promega) was included in the transfection mix. All transfections were done in triplicate with a total amount of $1 \mu \mathrm{g}$ of DNA per three wells. Nodal was produced from a BMP-Nodal fusion gene using the pre-pro hormone sequences from BMP-4 linked to the mature region of mouse Nodal, kindly provided by Michael Kuehn (National Institutes of Health, Bethesda, MD). Thirty-six hours after transfection, luciferase activity was analyzed using the Dual-Luciferase Reporter Assay System (Promega) in a 1450 Microbeta Jet counter (Wallac).

\section{Acknowledgments}

We thank Dan Kessler, Elaine Joseph, Chris Wright, Michael Kuehn, and Peter ten Dijke for providing plasmids, and members of the Brivanlou and Ibáñez laboratories for helpful comments and critical reading of the manuscript. Financial support was obtained from the National Institutes of Health grants PHS HD32105 and PHS EY12370 (to A.H.B), the Swedish Medical Research Council (K99-33X-10908-06C), Swedish Cancer Society (3474-B97-05XBC), Göran Gustafssons Stiftelse, and the Karolinska Institute (to C.F.I.), and a grant from the Associazione Italiana Ricerca sul Cancro AIRC (to M.G.P.). A.H.B. is supported by the Merck and Knigelstein foundation. E.R. is supported by a Bristol-Meyer Rockefeller Fellowship. A.B. was supported by the Swedish National Network in Neuroscience (NNN).

The publication costs of this article were defrayed in part by payment of page charges. This article must therefore be hereby marked "advertisement" in accordance with 18 USC section 1734 solely to indicate this fact.

\section{References}

Agius, A., Oelschlager, M., Wessly, O., Kemp, C., and De Robertis, E.M. 2000. Endodermal Nodal-related signals and mesoderm induction in Xenopus. Development 127:11731183.

Armes, A. and Smith, J.C. 1997. The ALK-2 and ALK-4 Activin receptors transduce distinct mesoderm-inducing signals during early Xenopus development but do not co-operate to establish thresholds. Development 124: 3797-3804.

Capdevila, J., Vogan, K.J., Tabin, C.J., and Izpisua Belmonte, J.C. 2000. Mechanisms of left-right determination in vertebrates. Cell 101: 9-21.

Chang, C. and Hemmati-Brivanlou, A. 1999. Xenopus GDF6, a new antagonist of noggin and a partner of BMPs. Development 126: 3347-3357.

Chang, C., Wilson, P.A., Mathews, L.S., and Hemmati-Brivanlou, A. 1997. A Xenopus type I receptor mediates mesodermal but not neural specification during embryogenesis. Development 124: 827-837. 
Conlon, F.L., Lyons, K.M., Takaesu, N., Barth, K.S., Kispert, A., Herrmann, B., and Robertson, E.J. 1994. A primary requirement for nodal in the formation and maintenance of the primitive streak in the mouse. Development 120: 19191928.

Dennler, S., Itoh, S., Vivien, D., ten Dijke, P., Huet, S., and Gauthier, J. M. 1998. Direct binding of smad3 and smad4 to critical TGF- $\beta$-inducible elements in the promoter of human plasminogen activator inhibitor-type 1 gene. EMBO $J$. 17: 3091-3100.

Ding, J., Yang, L., Yan, Y.T., Chen, A., Desai, N., WynshawBoris, A., and Shen, M.M. 1998. Cripto is required for correct orientation of the anterior-posterior axis in the mouse embryo. Nature 395: 702-707.

Dyson, S. and Gurdon, J.B. 1997. Activin signaling has an early function in Xenopus early development. Curr. Biol. 7: 81-84.

Erter, C.E., Solnica-Krezel, L., and Wright, C.V.E. 1998. Zebrafish nodal-related 2 encodes an early mesendodermal inducer signaling form the extraembryonic yolk syncytial layer. Dev. Biol. 204: 361-372.

Feldman, B., Gates, M.A., Egan, E.S., Dougan, S.T., Rennebeck, G., Sirotkin, H.I., Schier, A.F., and Talbot, W. 1998. Zebrafish organizer development and germ-layer formation require nodal-related signals. Nature 395: 181-185.

Gritsman, K., Zhang, J., Cheng, S., Heckscher, E., Talbot, W.S., and Schier, A.F. 1999. The EGF-CFC protein one-eyed pinhead is essential for nodal signaling. Cell 97: 121-132.

Gu, Z., Nomura, M., Simpson, B.B., Lei, H., Feijen, A., van den Eijnden-van Raaij, J., Donahoe, P.K., and Li, E. 1998. The type I activin receptor ActRIB is required for egg cylinder organization and gastrulation in the mouse. Genes \& Dev. 12: $844-857$.

Gurdon, J.B., Harger, P., Mitchell, A., and Lemaire, P. 1994. Activin signaling and response to a morphogen gradient. $\mathrm{Na}$ ture 371: 487-492.

Gurdon, J.B., Mitchell, A., and Mahony, D. 1995. Direct and continuous assessment by cells of their position in a morphogen gradient. Nature 376: 520-521.

Harland, R.M. and Gerhart, J. 1997. Spemann's organizer. Ann. Rev. Cell Dev. Biol. 13: 612-667.

Hatta, K., Kimmel, C.B., Ho, R.K., and Walker, C. 1991. The cyclops mutation blocks specification of the floor plate of the zebrafish central nervous system. Nature 350: 339-341.

Heasman, J., Crawford, A., Goldstone, K., Garner-Hamrick, P., Gumbiner, B., McCrea, P., Kintner, C., Noro, C.Y., and Wylie, C. 1994. Overexpression of cadherins and underexpression of beta-catenin inhibit dorsal mesoderm induction in early Xenopus embryos. Cell 79: 791-803.

Heisenberg, C.P. and Nuesslein-Vollhard, C. 1997. The function of silberblick in the positioning of the eye anlage in the zebrafish embryo. Dev. Biol. 184: 85-94.

Hemmati-Brivanlou, A. and Melton, D. 1994. Inhibition of activin receptor signaling promotes neuralization in Xenopus. Cell 77: 273-281.

Hemmati-Brivanlou, A., Wright, D.A., and Melton, D.A. 1992. Embryonic expression and functional analysis of a Xenopus Activin receptor. Dev. Dyn. 194: 1-11.

Hemmati-Brivanlou, A., Kelly, O.G., and Melton, D.A. 1994 Follistatin, an antagonist of Activin, is expressed in the Spemann organizer and displays direct neuralizing activity. Cell 77: 283-295.

Jones, C.M., Kuehn, M.R., Hogan, B.L.M., Smith, J.C., and Wright, C.V.E. 1995. Nodal-related signals induce axial mesoderm and dorsalize mesoderm during gastrulation. Development 121: 3651-3662.

Jörnvall, H., Blokzijl, A., ten Dijke, P., and Ibáñez, C. F. 2001.
The orphan receptor serine-threonine kinase ALK7 signals arrest of proliferation and morphological differentiation in a neuronal cell line. J. Biol. Chem. 276: 5140-5146.

Joseph, E.M. and Melton, D.A. 1997. Xnr4: A Xenopus Nodalrelated gene expressed in the Spemann organizer. Dev. Biol 184: 367-372.

Kimelman, D. and Griffin, K.J. 2000. Vertebrate mesendoderm induction and patterning. Curr. Opin. Genet. Dev. 10: 350356.

Kingsley, D.M. 1994. The TGF $\beta$ superfamily: New members, new receptors, and new genetic tests of function in different organisms. Genes \& Dev. 8: 133-146.

Kinoshita, N., Minshull, J., and Kirschner, M.W. 1995. The identification of two novel ligands of the FGF receptor by a yeast screening method and their activity in Xenopus development. Cell 83: 621-630.

Kunkel, T. 1985. Rapid and efficient site-specific mutagenesis without phenotypic selection. Proc. Natl. Acad. Sci. 82: 488492.

Lemaire, P., Darras, S., Caillol, D., and Kodjabachian, L. 1998. A role for the vegetally expressed Xenopus gene Mix.1 in endoderm formation and in the restriction of mesoderm to the marginal zone. Development 125: 2371-2380.

Lowe, L.A., Supp, D.M., Sampath, K., Yokoyama, T., Wright, C.V.E., Potter, S.S., Overbeck, P., and Kuehn, M.R. 1996. Conserved left-right asymmetry of Nodal expression and alterations in murine situs inversus. Nature 381: 158-161.

Lustig, K.D., Kroll, K., Sun, E., Ramos, R., Elmendorf, H., and Kirschner, M.W. 1996. A Xenopus Nodal-related gene that acts in synergy with noggin to induce complete secondary axis and notochord formation. Development 122: 3275 3282.

Mahony, D. and Gurdon, J.B. 1995. A type I serine/threonine kinase receptor that can dorsalize mesoderm in Xenopus. Proc. Natl. Acad. Sci. 92: 6474-6478.

Mahony, D., Weis, F.M.B., and Massagué, J., and Gurdon, J.B. 1998. XTrR-I is a TGF $\beta$ receptor and overexpression of a truncated form of the receptor inhibits axis formation and dorsalizing activity. Mech. Dev. 75: 95-105.

Massagué, J. 1998. TGF- $\beta$ signal transduction. Ann. Rev. Biochem. 67: 753-791.

Mathews, L.S., Vale, W.W., and Kintner, C.R. 1992. Cloning of a second type of Activin receptor and functional characterization in Xenopus embryos. Science 255: 1702-1705.

Matzuk, M.M., Kumar, T.R., Vassalli, A., Bickenbach, J.R., Roop, D.R., Jaenisch, R., and Bradley, A. 1995a. Functional analysis of activins during mammalian development, $\mathrm{Na}$ ture 374: 354-356.

Matzuk, M. M., Kumar, T.R., and Bradley, A. 1995b. Different phenotypes of mice deficient in either activins or activin receptor type II. Nature 374: 356-360.

Minchiotti, G., Parisi, S., Liguori, G., Signore, M., Lania, G., Adamson, E.D., Lago, C.T. and Persico, M.G. 2000 Membrane-anchorage of Cripto protein by glycosylphosphatidylinositol and its distribution during early mouse development. Mech. Dev. 90: 133-142.

Mohun, T.J., Garrett, N., and Gurdon, J.B. 1986. Upstream sequences required for tissue-specific activation of the cardiac actin gene in Xenopus laevis embryos. EMBO J. 5: 3185-3193.

New, H.V., Kavka, A.I., Smith, J.C., and Green, J.B. 1997. Differential effects on Xenopus development of interference with type IIA and type IIB Activin receptors. Mech. Dev. 61: $175-186$.

Nieuwkoop, P.D. and Faber, J. 1967. Normal table of Xenopus laevis Daudin. North Holland Publishing Company, Amsterdam, The Netherlands. 
Nishimatsu, S., Oda, S., Murakami, K., and Ueno N. 1992a. Multiple genes for Xenopus Activin receptor expressed during early embryogenesis. FEBS Lett. 303: 81-84.

Nishimatsu, S., Iwao, M., Nagai, T., Oda, S., Suzuki, A., Asashima, M., Murakami, K., and Ueno, N. 1992b. A carboxyl-terminal truncated version of the Activin receptor mediates Activin signals in early Xenopus embryos. FEBS Lett. 312: $169-173$.

Nomura, M. and Li, E. 1998. Smad2 role in mesoderm formation, left-right patterning and craniofacial development. $\mathrm{Na}$ ture 393: 786-790.

Oh, S.P. and Li, E. 1997. The signaling pathway mediated by the type IIB activin receptor controls axial patterning and lateral asymmetry in the mouse. Genes \& Dev. 11: 1812-1826.

Osada, S.I. and Wright, C.V.E. 1999. Xenopus Nodal-related signaling is essential for mesendodermal patterning during early embryogenesis. Development 126: 3229-3240.

Peyrieras, N., Strahle, U., and Rosa, F. 1998. Conversion of zebrafish blastomeres to an endodermal fate by TGF- $\beta$-related signaling. Curr. Biol. 8: 783-786.

Piccolo, S., Agius, E., Leyns, L., Bhattacharyya, S., Grunz, H., Bouwmeester, T., and De Robertis, E.M. 1999. The head inducer Cerberus is a multifunctional antagonist of Nodal, BMP and Wnt signals. Nature 397: 707-710.

Ramsdell, A.F. and Yost, H.J. 1999. Cardiac looping and the vertebrate left-right axis: Antagonism of left-sided Vg1 activity by a right-sided ALK2-dependent BMP pathway. Development 126: 5195-5205.

Rebagliati, M.R., Toyama, R., Fricke, C., Haffter, P., and Dawid, I.B. 1998a. Zebrafish nodal-related genes are implicated in axial patterning and establishing left-right asymmetry. Dev. Biol. 199: 261-272.

Rebagliati, M.R., Toyama, R., Haffter, P., and Dawid, I.B. 1998b. Cyclops encodes a nodal-related factor involved in midline signaling. Proc. Natl. Acad. Sci. 95: 9932-9937.

Rydén, M., Imamura, T., Jörnvall, H., Belluardo, N., Neveu, I., Trupp, M., Okadome, T., ten Dijke, P., and Ibáñez, C.F. 1996. A novel type I receptor serine-threonine kinase predominantly expressed in the adult central nervous system. J. Biol. Chem. 271: 30603-30609.

Sampath, K., Cheng, A.M.S., Frisch, A., and Wright, C.V.E. 1997. Functional differences among Xenopus Nodal-related genes in left-right axis determination. Development 124: 3293-3302.

Sampath, K., Rubinstein, A.L., Cheng, A.M.S., Liang, J.O., Fekar, K., Solnica-Krezel, L., Korzh, V., Halpern, M.E., and Wright, C.V.E. 1998. Induction of the zebrafish ventral brain and floor plate requires cyclops/Nodal signaling. Nature 395: 185-189.

Sasai, Y., Lu, B., Steinbeisser, H., Geissert, D., Gont, L.K., and DeRobertis, E.M. 1994. Xenopus chordin: A novel dorsalizing factor activated by organizer-specific homeobox genes. Cell 79: 779-790.

Schulte-Merker, S., Smith, J.C., and Dale, L. 1994. Effects of truncated activin and FGF receptors and of follistatin on the inducing activities of BVg1 and activin: Does activin play a role in mesoderm induction? EMBO J. 13: 3533-3541.

Shen, M.M. and Schier, A.F. 2000. The EGF-CFC gene family in vertebrate development. Trends Genet. 16: 303-309.

Shi, Y., Katsev, S., Cai, C., and Evans, S. 2000. BMP signaling is required for heart formation in vertebrates. Dev. Biol. 224: 226-237.

Smith, J.C., Price, B.M., Green, J.B., Weigel, D., and Hermann, B.G. 1991. Expression of Xenopus homolog Brachyury T is an immediate-early resprons to mesoderm induction. Cell 67: 79-87.
Smith, W.C., McKendry, R., Ribisi, Jr., S., and Harland, R.M. 1995. A nodal-related gene defines a physical and functional domain within the Spemann organizer. Cell 82: 37-46.

Song, J., Oh, S.P., Schrewe, H., Nomura, M., Lei, H., Okano, M., Gridley, T., and Li, E. 1999. The type II Activin receptors are essential for egg cylinder growth, gastrulation and rostral head development in mice. Dev. Biol. 213: 157-169.

Takahashi, S., Yokoto, C., Takano, K., Tanegashima, K., Onuma, Y., Goto, J.I., and Asashima, M. 2000. Two novel nodal-related genes initiate early inductive events in Xenopus Nieuwkoop center. Development 127: 5319-5329.

Thisse, C., Thisse, B., Halpern, M.E., and Postlethwait, J.H. 1994. Goosecoid expression in neuroectoderm and mesoderm is disrupted in zebrafish cyclops gastrulas. Dev. Biol. 164: 420-429.

Thomson, G., Woolf, T., Whitman, M., Sokol, S., Vaughan, J., Vale, W., and Melton, D.A. 1990. Activins are expressed early in Xenopus embryogenesis and can induce axial mesoderm and anterior structures. Cell 63: 485-493.

Tsuchida, K., Sawchenko, P.E., Nishikawa, S., and Vale, W.W. 1996. Molecular cloning of a novel Type I receptor serine/ threonine kinase of the TGF $\beta$ superfamily from Rat Brain. Mol. Cell. Neurosci. 7: 467-478.

Watanabe, R., Yamada, Y., Ihara, Y., Someya, Y., Kubota, A., Kagimoto, S., Kuroe, A., Iwakura, T., Shen, Z., Inada, A., et al. 1999. The MH1 domains of smad2 and smad 3 are involved in the regulation of the ALK7 signals. Biochem. Biophys. Res. Commun. 254: 707-712.

Weeks, D.L. and Melton, D.A. 1987. A maternal mRNA localized to the vegetal hemisphere in Xenopus eggs codes for a growth factor related to TGF $\beta$. Cell 51: 861-867.

Wright, C.V., Morita, E.A., Wilkin, D.J., and De Robertis, E.M. 1990. The Xenopus XlHbox6 homeoprotein, a marker of posterior neural induction, is expressed in proliferating neurons. Development 109: 225-234.

Yasuo, H. and Lemaire, P. 1999. A two-step model for the fate determination of presumptive endodermal blastomeres in Xenopus embryos. Curr. Biol. 9: 869-879.

Zhou, X., Sasaki, H., Lowe, L., Hogan, B.L., and Kuehn, M.R. 1993. Nodal is a novel TGF- $\beta$-like gene expressed in the mouse node during gastrulation. Nature 361: 543-547. 


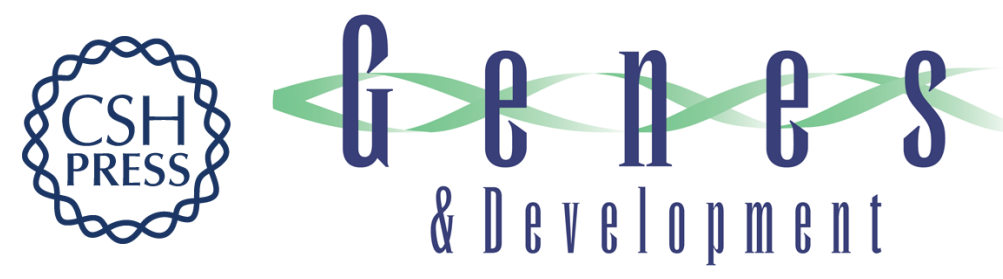

\section{The orphan receptor ALK7 and the Activin receptor ALK4 mediate signaling by Nodal proteins during vertebrate development}

Eva Reissmann, Henrik Jörnvall, Andries Blokzijl, et al.

Genes Dev. 2001, 15:

Access the most recent version at doi:10.1101/gad.201801

References This article cites 70 articles, 23 of which can be accessed free at: http://genesdev.cshlp.org/content/15/15/2010.full.html\#ref-list-1

License

Email Alerting

Receive free email alerts when new articles cite this article - sign up in the box at the top Service right corner of the article or click here.

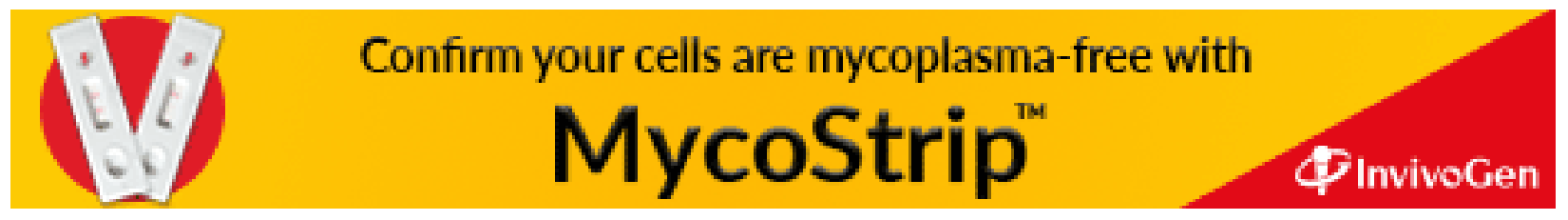

